\title{
Chemometric Characterization of Eight Monovarietal Algerian Virgin Olive Oils
}

\author{
Mokhtar Guissous $^{1} \cdot$ Yveline Le Dréau $^{2} \cdot$ Hasna Boulkhroune $^{1} \cdot$ Toufik Madani $^{1} \cdot$ Jacques Artaud $^{2}$
}

\begin{abstract}
Differences in triacylglycerol, fatty acid, squalene, and tocopherol compositions were demonstrated between 8 varieties of virgin olive oils (Aberkane, Aguenaou, Aharoun, Aimel, Bouchouk Guergour, Bouichret, Chemlal, and Sigoise) from Petite Kabylie area, north eastern Algeria. Fatty acid and triacylglycerol morphotypes characterized each variety. A principal component analysis, based on triacylglycerol, fatty acid, and squalene compositions, differentiates between varieties. Minor fatty acids and squalene, usually not taken into account individually in authentication studies, are strongly involved in this differentiation, whereas the discriminant power of tocopherols is weak. Soft Independent Modeling of Class Analogy classification using chemical compositions as variables showed a high potential to authenticate the varietal origin of Algerian virgin olive oils.
\end{abstract}

Keywords Fatty acids - Triacylglycerols - Minor compounds · Characterization · Chemometrics · Algerian virgin olive oils

J Am Oil Chem Soc (2018) 95: 267-281.

\begin{tabular}{|c|c|}
\hline $16: 1 \omega 7$ & hypogeic acid (9-hexadecenoic acid) \\
\hline $17: 0$ & margaric acid (heptadecanoic acid) \\
\hline $17: 1 \omega 8$ & margaroleic acid (9-heptadecenoic acid) \\
\hline 18:0 & stearic acid (octadecanoic acid) \\
\hline $18: 1 \omega 9$ & oleic acid (9-octadecenoic acid) \\
\hline $18: 1 \omega 7$ & cis vaccenic acid (11-octadecenoic acid) \\
\hline $18: 2 \omega 6$ & linoleic acid $(9,12$-octadecadienoic acid $)$ \\
\hline $18: 3 \omega 3$ & $\begin{array}{l}\text { linolenic acid } \quad(9,12,15 \text {-octadecatrie- } \\
\text { noic acid })\end{array}$ \\
\hline 20:0 & arachidic acid (eicosanoic acid) \\
\hline $20: 1 \omega 9$ & gondoic acid (11-eicosenoic acid) \\
\hline $22: 0$ & behenic acid (docosanoic acid) \\
\hline 24:0 & lignoceric acid (tetracosanoic acid) \\
\hline SFA & saturated fatty acids \\
\hline MUFA & mono unsaturated fatty acids \\
\hline PUFA & poly unsaturated fatty acids \\
\hline OFA & odd fatty acids \\
\hline Triacylglycerols & $\begin{array}{l}\text { The triacylglycerols (TAG) are desig- } \\
\text { nated by three letters corresponding to } \\
\text { abbreviated names of fatty acid carbon } \\
\text { chains that are fixed on the glycerol. The } \\
\text { abbreviations of fatty acids names are: }\end{array}$ \\
\hline $\mathrm{P}$ & palmitoyl \\
\hline Po & palmitoleyl \\
\hline $\mathrm{S}$ & stearoyl \\
\hline $\mathrm{O}$ & oleoyl \\
\hline $\mathrm{L}$ & linoleoyl \\
\hline Ln & linolenoyl \\
\hline A & arachidoyl \\
\hline
\end{tabular}

\section{Introduction}

Algeria is the sixth olive oil producer after the EU, Tunisia, Syria, Turkey, and Morocco. In all, 6.2 million trees were 
counted, representing an area of 471,657 ha, increasing steadily in recent years (ONFAA Bilan de la campagne oléicole 2015/2016, 2016). The average production over the years 2009-2010 to 2014-2015 has been equivalent to $52,100 \mathrm{t}$ or $1.8 \%$ of the world production, and the consumption for the same period to $51,400 \mathrm{t}$ or $1.7 \%$ of the world consumption (International Olive Council, 2015a). Algerian olive growing remains on old production patterns that make it uncompetitive. It is largely owing to small family farming and mountain farming. The major part of the olive orchards is located in mountainous areas (Kabylie, 55\%) where own-consumption is widely seen (Hadjou, Lamani, \& Cheriet, 2013). Moreover, as its quality often does not comply with the "virgin olive oil" category of the international standards, it is not easy to export the oil produced in Algeria. For the 2014-2015 marketing year, only $7.48 \%$ of the oil produced belonged to the category "extra virgin olive oil" and $37.43 \%$ to the category "virgin olive oil" (ONFAA Bilan de la campagne oléicole 2015/2016, 2016). In 2010, the Ministry of Agriculture and Rural Development has sought to revitalize the olive oil sector, considered a major objective, by supporting a planting program of olive trees on 1 million hectares.

Despite its handicaps, Algerian olive growing has significant diversity and quantity of varieties. They are grown in the coastal areas of Algeria. More than 150 local varieties of olive trees were counted (Douzane, Nouani, Dako, \& Bellal, 2012). This number may be slightly high, as the catalogue of the Technical Institute of Fruit Trees and Vines (ITAF) only describes 36 varieties, and only five varieties among the main (Azeradj, Blanquette de Guelma, Chemlal of Kabylie, Limli, Sigoise) are included in the World Catalogue of Olive Varieties (2000). The majority (75\%) of the national olive-growing area is planted with three varieties: Chemlal (40\%), Sigoise (25\%), and Azeradj (10\%) (Louadj \& Giuffre, 2010). Chemlal and Azeradj are located in the center and the east of the country (Kabylie) while Sigoise is in the west.

Only few data on the chemical composition of the Algerian olive oils are available and they are often incomplete or false. Some studies provide quality indices, fatty acid compositions, phenolic compounds, and tocopherols for the varieties Aghenfas, Azeradj, Bouichret, Chemlal, Grosse Hamma, Limli, Sigoise, Tahesrit, and for four oleaster populations (Bakhouche, Lozano-Sánchez, Bengana, FernándezGutiérrez, \& Segura-Carretero, 2015; Bouarroudj, Tamendjari, \& Larbat, 2016; Douzane et al., 2012; Laincer et al., 2016; Louadj \& Giuffre, 2010; Moussaoui, Labbaci, Hemar, Youyou, \& Amir, 2008). Pigments (chlorophylls and carotenoids) were determined in three varieties: Chemlal, Sigoise, and Tabelout (Zegane, Keciri, \& Louaileche, 2015). Sterols, methyl sterols, and triterpenic alcohols were analyzed in three varieties of eastern Algeria (Mezghache et al., 2010).
Many spectral and physicochemical techniques were used for the characterization and authentication of olive oils (Wang, Sun, Zhang, \& Liu, 2016). The vibrational spectroscopic techniques (Mid-infrared, Near-Infrared, and Raman) provide rapid analysis of oils even if they do not enable to reach the quality of some chemical analyses. Quality indices (acidity, peroxide value, $\mathrm{K}_{232}$, and $\mathrm{K}_{270}$ ) and compositions of phenolic compounds, pigments, and volatile compounds depend on a large number of parameters such as the fruit ripeness, the method of oil extraction, or its preservation; therefore, it is difficult to use them to determine the varietal origin of olive oils. In contrast, the triacylglycerol (TAG), fatty acid, and squalene compositions of oils are stable during extraction and conservation processes, thereby allowing their use to characterize and authenticate olive oils (Laroussi-Mezghani et al., 2015; Ollivier, Artaud, Pinatel, Durbec, \& Guérère, 2003; Ollivier, Artaud, Pinatel, Durbec, \& Guérère, 2006). In addition, although the literature data show a wide range of tocopherol levels that seem to depend on olive cultivars, tocopherol isomers are generally not considered in authentication studies.

The aim of this work was to characterize Algerian virgin olive oils (VOOs) from eight cultivars (Aberkane, Aguenaou, Aharoun, Aimel, Bouchouk Guergour, Bouichret, Chemlal, and Sigoise) seven of which are not included in the World Catalogue of Olive Varieties, and on which only few studies have been conducted. Their TAG and fatty acid compositions as well as their squalene and tocopherol contents have been determined. Data have been used to research discriminating criteria between monovarietal olive oil from these varieties.

\section{Materials and Methods}

\section{Virgin Olive Oil Samples}

Monovarietal olive oil samples were extracted from eight varieties of olives in monovarietal orchards located in the valley of Oued Mhadjer, Bousselam and Soumman, and Petite Kabylie, in northeastern Algeria (36.3408 N, 4.7753 E). The orchards are located at an altitude between 360 and $600 \mathrm{~m}$. Sampling from each variety was performed from hand-picked olives (about $3 \mathrm{~kg}$ each) during the 2015-2016 harvest. The collection was performed on the same trees at four dates (30 September, 15 October, and 1 and 16 November) to be sure that the ripening stage do not influence the varietal authentication. VOO were obtained using a laboratory extraction system (MC2 Ingenieria y Sistemas S. L., Sevilla, Spain) called oleodoseur, composed of crusher, vertical malaxor, and centrifuge. The olive storage time was less than $24 \mathrm{~h}$. The oil samples 
obtained were stored after filtration at $4{ }^{\circ} \mathrm{C}$ in full bottles. In all, 127 olive oil samples from eight varieties have been obtained (Aberkane (Ab), $\mathrm{n}=16$; Aguenaou (Ag), $\mathrm{n}=16$; Aharoun (Ah), n = 16; Aimel (Ai), n = 16; Bouchouk Guergour $(\mathrm{Bk}), \mathrm{n}=16$; Bouichret $(\mathrm{Bt}), \mathrm{n}=16$; Chemlal $(\mathrm{Ch})$, $\mathrm{n}=16$; Sigoise $(\mathrm{Si}), \mathrm{n}=15)$.

\section{Maturity Index}

The maturity index (MI) allows an estimation of ripening stage of olives. It was determined according to the method described in the guide for the determination of the characteristics of oilolives (International Olive Council, 2011) based on the visual evaluation of the olive skin and pulp colors of 100 olive fruits varying on a scale from 0 (green-intense) to 7 (black).

\section{Agronomic Characters}

The average weight of olives ( $g$ ) was determined with 120 olives. Total oil content (\%), Oil free dry matter (OFDM, \%) and Moisture (\%) were determined according to the guide for the determination of the characteristics of oil-olives (International Olive Council, 2011). Biological yield (BY) is the ratio of the oil content to the oil-free dry matter content. This ratio, used by the Association Française Inter-professionnelle de l'Olive (AFIDOL, Aix-enProvence, France), measures the ability of a variety of olive fruits to elaborate oil. It makes it possible to compare varieties: the higher this ratio is, the more the variety is able to produce oil (Moutier et al., 2004).

\section{Physicochemical Characteristics}

Free acidity (A) (g oleic acid/100 g olive oil), peroxide value $(\mathrm{PV})\left(\mathrm{meqO}_{2} / \mathrm{kg}\right)$, and UV-specific absorption $\left(\mathrm{K}_{232}\right.$ and $\mathrm{K}_{270}$ ) were determined according to the International Olive Council (2015b).

\section{Triacylglycerol Compositions}

TAG were analyzed by a HPLC with a LC Agilent 1200 series system (Agilent, Santa Clara, California, USA), operated with Chemstation software (Agilent, Santa Clara, California, USA), equipped with an autosampler, a quaternary pump, a column heater module $\left(28{ }^{\circ} \mathrm{C}\right)$, a RID detector (Agilent, Santa Clara, California, USA), and a Merck RP18 Supersphere 100 column $(250 \times 4 \mathrm{~mm}$ i.d., $4 \mu \mathrm{m})$ (Merck KGaA, Darmstadt, Germany). The mobile phase was propionitrile (ACRŌS Organics, Geel, Belgium) with a flow rate linear gradient $\left(0.5-1.0 \mathrm{~mL} \mathrm{~min}^{-1}\right)$ for $47 \mathrm{~min}$. Oil samples of $10 \mu \mathrm{L}$ each in propionitrile $(5 \%$, w/v) were injected. TAG in olive oils were separated according to equivalent carbon number (ECN), often defined as $\mathrm{CN}-2 n$, where $\mathrm{CN}$ is the carbon number and $n$ is the number of double bonds. TAG identification was carried out in a previous work (Ollivier et al., 2006).

\section{Fatty Acid and Squalene Compositions}

Approximately $0.120 \mathrm{~g}$ of VOO (accurately weighed, \pm $0.001 \mathrm{~g}$ ) in 2,2,4-trimethylpentane (isooctane, $2 \mathrm{~mL}$ ) was trans-methylated with a cold solution of $\mathrm{KOH}(2 \mathrm{M} ; 200 \mu \mathrm{L})$ according to the European Standard, NF EN ISO 12966-2 (2011). Fatty acid methyl ester (FAME) analyses were performed on an Agilent Technology gas chromatograph 7890A (Agilent, Santa Clara, California, USA) (GC) equipped with a split/split-less injector $\left(T=250{ }^{\circ} \mathrm{C}\right)$ and flame ionization detector (FID) $\left(T=250{ }^{\circ} \mathrm{C}\right)$. A silica capillary column (60 $\mathrm{m} \times 0.25 \mathrm{~mm}$ i.d., $0.25 \mu \mathrm{m}$ film thickness) coated with polyethylene glycol (Supelcowax, Supelco, Bellefonte, Pennsylvania, USA) was used. The carrier gas was hydrogen (column flow $1 \mathrm{~mL} \mathrm{~min}^{-1}$ ), and the split ratio was 1:60. The oven temperature was programmed as follows: $20 \mathrm{~min}$ at $210{ }^{\circ} \mathrm{C}$, from 210 to $245^{\circ} \mathrm{C}$ at $6{ }^{\circ} \mathrm{C} / \mathrm{min}, 20 \mathrm{~min}$ at $245^{\circ} \mathrm{C}$. The identification of fatty acids was carried out in a previous work (Ollivier et al., 2003). Fatty acid percentages were determined by internal standardization without taking into account mass response factors. The coefficients of variation in fatty acid percentages were lower than $5 \%$ for the most important FAME and lower than $10 \%$ for some minor ones.

Squalene was analyzed by gas chromatography, at the same time as the fatty acid methyl esters. The quantification method is easy to implement and requires no additional sample preparation. Squalene is well separated from lignoceric acid (24:0) (retention times 38.48 and $37.55 \mathrm{~min}$, respectively). It was determined along with the fatty acids using an external standard calibration curve (squalene in isooctane: $0.041-0.612 \mathrm{mg} \mathrm{mL}^{-1}$; Eq. 1).

$S=193.73 C_{S}+0.58$

where $S$ is the peak area of squalene and $C_{S}$ is the concentration expressed in $\mathrm{mg} \mathrm{mL}^{-1}$ (linearity $0.030-0.62 \mathrm{mg}$ $\left.\mathrm{mL}^{-1}, R^{2}=0.999\right)$. Final results, calculated on the basis of the analyzed oil weight, were expressed in $\mathrm{mg} \mathrm{kg}^{-1}$ with a coefficient of variation equal to $1.5 \%$ according to the experimental error.

\section{Mean Indexes}

Four indexes characterizing the VOO fatty acids were calculated to facilitate the comparison between samples. They are defined below:

- Saturated fatty acids (SFA) is the sum of saturated fatty acids, 
- Mono-unsaturated fatty acids (MUFA) is the sum of mono-unsaturated fatty acids,

- Poly-unsaturated fatty acids (PUFA) is the sum of poly-unsaturated fatty acids,

- Odd fatty acids (OFA) is the sum of the odd fatty acids

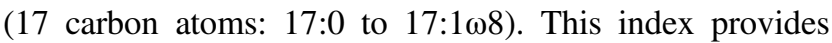
fine information on the content of odd fatty acids, which are not accessible with the indices conventionally used.

\section{"Morphogram" and "Morphotype"}

Morphogram of fatty acid or TAG variables is an optimized graphical radial representation of the composition of 14 fatty acids or 19 TAG of a given olive oil sample; it is a tool that swiftly enables its varietal origin recognition, based on the difference between TAG or fatty acid values obtained for this sample compared to the average of the same variable of a database built with more than 3500 samples from various sources collected over 15 crop years, grouped by variety and origin (Pinatel, Ollivier, Ollivier, \& Artaud, 2014). Each axis illustrates one variable. Note that $0 \%$ corresponds to the center of its range of variation in the database; it is the truncated mean (calculated from $25 \%$ of the values positioned positively and negatively around the median) to which the absolute difference between the mean and the median was added, in order to take into account the natural dissymmetry of the sample base (Pinatel et al., 2014). The lower and upper limits (i.e. $\pm 100 \%$ ) were respectively calculated by subtracting or adding twice the SD at this central value. The value of a variable for a specific sample is the ratio between its deviation from the central value and the absolute value of the maximum deviation from the central value in the database. The morphotypes are developed alike as the morphograms with the values of fatty acids or TAG of at least five oil samples $(n \geq 5)$ from the same variety. Therefore, the plane line describes the median values of individual TAG and fatty acids and the dotted lines, the first and the third quartiles. Morphograms (sample fingerprint) and morphotypes (varietal fingerprint) were performed with Excel 2003 spreadsheet (Microsoft Corporation).

\section{Tocopherol Contents}

Determination of tocopherols was based on the analysis by normal phase HPLC of oil samples with an optimization of the standard method (European standard NF EN ISO 9936, 2006). A weighed quantity of VOO sample (0.700 \pm $0.001 \mathrm{~g}$ ) was dissolved in a $5 \mathrm{~mL}$ volumetric flask with hexane/2-propanol (99/1, v/v) and $20 \mu \mathrm{L}$ was injected on a LC Agilent 1200 series system, operated with Chemstation software, equipped with an auto-sampler, a quaternary pump, column heater module $\left(25^{\circ} \mathrm{C}\right)$, and a photodiode array (DAD) detector connected in series with a multiwavelength fluorescence detector (FLD). Separation was achieved on LiChrospher-Si 60 column $(250 \times 4 \mathrm{~mm}$ i. d., $5 \mu \mathrm{m}$ ) (Merk, KGaA, Darmstadt, Germany) with a hexane/2-propanol (99/1, v/v) mobile phase at $1 \mathrm{~mL} \mathrm{~min}^{-1}$ flow rate. UV detection wavelength was programmed at $292 \mathrm{~nm}$ and fluorescence detection was performed at excitation and emission wavelengths of 295 and $330 \mathrm{~nm}$, respectively. The identification of the constituents was based on the comparison of the retention times with those of standards (Tocopherols mixed, Sigma-Aldrich, Steichein, Germany). As $\alpha$-tocopherol is much more abundant in the samples than $\beta$ and $\gamma$ tocopherols, and as the FLD is much more sensitive than the DAD, two calibration ranges were used in order to express $\alpha, \beta$, and $\gamma$ tocopherol contents as mg equiv. $\alpha$-tocopherol $\mathrm{kg}^{-1}$ from the same sample injection. $\alpha$-Tocopherol content was determined using the following external standard calibration curve (Eq. 2):

$A_{d}=8612 C+8$

$A_{d}$ is the peak area of $\alpha$-tocopherol measured on DAD signal and $C$ is its concentration expressed in $\mathrm{mg} \mathrm{mL}^{-1}$ (linearity $0.010-0.055 \mathrm{mg} \mathrm{mL}^{-1}, R^{2}=0.996$ ).

The $\beta$ - and $\gamma$-tocopherol contents were determined using the external standard calibration curve of $\alpha$-tocopherol measured on FLD signal (Eq. 3):

$A_{f}=246,233 C-28$

$A_{f}$ is the peak area of $\alpha$-tocopherol measured on FLD signal and $C$ is its concentration expressed in $\mathrm{mg} \mathrm{mL}^{-1}$ (linearity 0.0004 to $\left.0.0035 \mathrm{mg} \mathrm{mL}^{-1}, R^{2}=0.997\right)$.

Final results calculated with $\alpha$-tocopherol area measured on DAD signal and Eq. 2, $\beta$ - and $\gamma$-tocopherol areas measured on FLD signal and Eq. 3 and the oil weight were expressed in $\mathrm{mg}$ equiv. $\alpha$-tocopherol $/ \mathrm{kg}$ oil with a coefficient of variation equal to $1.5 \%$ according to the experimental error.

\section{Principal Component Analysis}

Principal component analysis (PCA) is a tool for unsupervised learning, e.g., extracting information directly from multidimensional table without referring to known classes (Jolliffe, 2002). To find these sources of variations, the original data matrix is decomposed into the sample space, the variable space, and the error matrix. PCA is to transform correlated variables into new variables (called "Principal Components" [PC]) uncorrelated to each other. PCA models lead to score plots and loading plots. The loadings are the correlation coefficients of the original variables with the $\mathrm{PC}$ while the scores represent the coordinates of the samples in the system of PC axes. The error matrix represents the variations not explained by the previously extracted PC and is dependent on the problem definition. 
PC describe in decreasing order the higher variations among the objects, and because they are calculated to be orthogonal to another one, each PC can be interpreted independently. That permits an overview of the data structure by revealing relationships between the objects as well as the detection of deviating objects. The PCA models of TAG and fatty acid percentages, squalene and tocopherol contents were calculated with normalized data. The graphical representation of the explained variance as function of PC is similar to a scree graph of Cattell. The place where the smooth increase appears to level off is the criterion used to retain the $\mathrm{PC}$ to analyze the data.

\section{Soft Independent Modeling of Class Analogy Classification}

Soft Independent Modeling of Class Analogy (SIMCA) is one of the most used supervised multivariate classification method for allocating unknown samples to the most probable class (Wold \& Sjöström, 1977). SIMCA is based on making a PCA model, in a defined calibration set of known samples, for each class, which describes the structure of that class as well as possible. A test stage uses significance tests to classify new known samples; as for unknown samples, they are compared to the class models and assigned to classes according to their proximity to the training samples. SIMCA is known as a supervised pattern recognition method as the individual PCA models define classification rules. The classification decision rule is based on a classical statistical approach. If a sample belongs to a class, it should have a small distance to the class model (the ideal situation being "distance $=0$ "). For this unknown sample, the aim is to compare its distance to a particular model and determine whether this distance lies within the class membership limit of the model. This is analogous to the probability distribution of object-to-model distances around zero.

A model distance limit Smax calculated for the class model " $\mathrm{m}$ " as follows (Eq. 4) is used for classifying unknown samples:

$\operatorname{Smax}(m)=S O(m) \sqrt{F_{c}}$

where $S 0$ is the average distance within the model, and $F C$ (Fisher criterion) is the critical value provided by the Fisher-Snedecor tables.

Class membership is defined at a significance level of $2.5 \%$ of Smax.

The SIMCA classification results are displayed in a classification membership table which contains as many columns as class models. Samples "recognized" as members of a class have a " 1 " in the corresponding column. The percentage of correct classification $(\% C C)$ is used as criterion to evaluate the quality of the classification of the test set (Eq. 5):
$\% C C=N c \cdot 100 /(N c+N i c)$

where $N c$ is the number of correct classifications and Nic is the number of incorrect classifications.

Two-thirds of the samples from the eight varieties were randomly selected to form the calibration set for disjoint PCA. The test set was formed with samples not used in the calibration set. Mean centering was applied before modeling. The $F c$ value was set to $5 \%$.

\section{Software}

The chemometric application was performed by the Unscrambler software version 10.3 from CAMO, Computer Aided Modelling, Trondheim, Norway.

\section{Results and Discussion}

\section{Agronomic Characters}

Table 1 gives some agronomic characters of eight Algerian VOO varieties. Aberkane, Aguenaou, and Bouchouk Guergour have large and heavy fruits, Aharoun, Bouichret, Chemlal, and Sigoise have medium weight fruits and Aimel has small fruits. However, this does not necessarily determine oil yield. Indeed, Aberkane, which has large fruit, also has large oil content; in contrast, Aguenaou, which has the heaviest fruits, produces less amount of oil, even if these samples have nearly the same mean MI. Moreover, Bouichret, with the greatest MI, also has poor oil content contrary to what is generally observed. The BY reflects the potential of a variety to produce oil. Aberkane and Bouchouk Guergour with BY of 0.95 and 0.91 respectively can be considered as high oil productive varieties. Aharoun (BY = 0.72), Aimel $(\mathrm{BY}=0.73)$, Chemlal $(\mathrm{BY}=0.65)$, and Sigoise $(\mathrm{BY}=0.76)$ have BY that are generally found for most varieties (Moutier et al., 2004). Aguenaou $(\mathrm{BY}=0.57)$ and Bouichret $(\mathrm{BY}=0.56)$ have the lowest values. Aguenaou, with highest dry matter content $(43.71 \%)$, has large kernels and therefore has a poor biological yield $(\mathrm{BY}=0.57)$.

\section{Physicochemical Characteristics}

Table 1 presents some physicochemical characteristics used to classify the oils into categories. These quality criteria depend on the olive quality before extraction, the quality of extraction and the oil storage conditions. Table 1 shows no significant differences in the quality parameters between the eight varieties. According to the commercial norm of the International Olive Council (2015b) for these criteria, 
all oil samples were classified in the category of extra VOO.

\section{Triacylglycerol Compositions}

TAG make up about $98 \%$ of olive oil, so TAG composition has a great importance in the characterization and the authentication of VOO. The composition of the 127 Algerian VOO samples from eight olive oil varieties was determined by liquid chromatography using propionitrile as mobile phase that allowed a better resolution between TAG (Ollivier et al., 2003) than the solvent acetone/acetonitrile recommended by the IUPAC method (International Union of Pure and Applied Chemistry, 1987). Nevertheless, some TAG are not separated yet. TAG identification was carried out at a precedent work (Ollivier et al., 2003). Table 2 gives variation ranges and the average value for 19 TAG variables (corresponding to 22 TAG because of coelutions) for each cultivar.

As all VOO, the 127 samples contain four main TAG representing over $70 \%$ of the total content of TAG with a more or less great variability according to the varieties. For the eight varieties, triolein (OOO), consistently most abundant, varies between 20.76 and 40.94\%, 1,2-dioleoyl3-palmitoyl-glycerol (POO) between 16.44 and $29.91 \%$, 1,3-dioleoyl-2-linoleoyl-glycerol (LOO) between 8.15 and $22.66 \%$, and 1-palmitoleoyl-2-linoleoyl-3-oleoyl-glycerol (PLO) between 5.47 and 12.14\%. Furthermore, based on the average contents of these main TAG, the samples are classified into three groups: Aharoun, Bouchouk Guergour, and Bouichret cultivars showed low contents of OOO and POO and high contents of LOO + PLnP and PLO + SLL; Aberkane and Sigoise cultivars showed a high content of OOO, low contents of POO and PLO + SLL, and a medium content of LOO + PLnP; Aguenaou, Aimel, and Chemlal showed medium contents of OOO and PLO + SLL, a high content of POO, and a low content of LOO + PLnP. More broadly, on the basis of all TAG, Sigoise has the highest percentages of TAG with steraoyl moiety and the lowest percentage of TAG with palmitoyl moiety; the samples from the Aharoun, Bouchouk Guergour, and Bouichret group have larger amounts of TAG with linoleoyl moiety that distinguishes them from others.

As the chromatographic separation of the TAG has shown some co-elutions, the determination of fatty acid composition is required.

\section{Fatty Acid Compositions}

Fatty acid composition has always had a great importance in the characterization and the authentication of olive oils and the detection of adulteration (Ollivier et al., 2003; Pinatel et al., 2014). Fourteen fatty acids were identified and quantified for the 127 Algerian VOO samples by gas chromatography of their methyl esters. Table 3 shows for each variety, the mean, minimum, and maximum percentages of each fatty acid. All samples showed that fatty acid levels conform to the IOC standard (International Olive Council, 2015b) except for Bouichret cultivar samples with rather high content of $17: 1 \omega 8(\geq 0.3 \%)$.

As all VOO, the 127 samples contain five main fatty

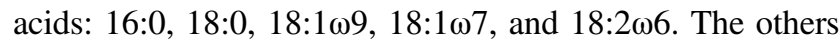
are considered as minor fatty acids $(<1 \%)$. Usually, the global content of $18: 1$ and 16:1 fatty acids is evaluated without distinction between the both structural isomers.

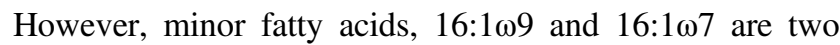
important criteria for distinction among cultivars (Pinatel et al., 2014). They vary markedly with variety.

SFA values are correlated with palmitic and stearic acids. Aberkane, Bouchouk Guergour, and Sigoise present the lower percentages of SFA (15.53-16.85\%). The other cultivars have SFA percentages higher than $18 \%$. MUFA values are correlated mainly with oleic acid. Aberkane and Sigoise VOO present the highest $(74.47 \%$ and $72.59 \%$, respectively) mean percentages in MUFA because of high content of $18: 1 \omega 9$ fatty acid (68.88-72.38\% and $69.76-72.01 \%$, respectively) and Aharoun, Bouchouk Guergour, and Bouichret VOO, the lowest $(62.87 \%, 64.81 \%$, and $64.45 \%$, respectively) because of their low percentages of 18:1 $\omega 9$ fatty acid. The lowest mean PUFA percentages were observed for Aimel, Aguenaou, and Aberkane varieties $(8.55 \%, 9.71 \%$, and $9.90 \%$, respectively) because of their lowest percentages of 18:2 $\omega 6$ fatty acid $(<10 \%)$. The other cultivars showed intermediate (Chemlal and Sigoise) or high PUFA percentages (Bouichret, Aharoun, and Bou-

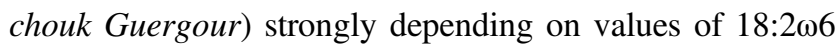
fatty acid because their percentages of 18:3 $\mathrm{\omega} 3$ fatty acid are always lower than $1 \%$. OFA characterizes the oil contents

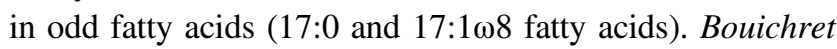
has the highest OFA (0.64\%); Bouchouk Guergour (0.44\%), Aberkane (0.36\%), Aharoun (0.34\%), and Aguenaou $(0.32 \%)$ have OFA intermediate values while those of Chemlal (0.12\%), Aimel (0.11\%), and Sigoise (0.11\%) indicate low levels of odd fatty acids.

Some fatty acids are indicators of a variety or group of varieties. Thus, mean percentages of 16:0 fatty acid are the highest for Aimel and Chemlal (17.51\% and $17.56 \%$, respectively), intermediate for Aberkane, Aguenaou, Aharoun, Bouchouk Guergour, and Bouichret (12.34-15.82\%) and the lowest for Sigoise (10.31\%). Aguenaou (4.74\%), Aimel (4.94\%), and Chemlal (6.06\%) have high mean percentages of $\omega 7$ fatty acids $(16: 1 \omega 7+18: 1 \omega 7)$. For these varieties, the mean percentage of 18:1 $\omega 7$ fatty acid is higher than 18:0 fatty acid. Sigoise oil has the highest mean percentages of 18:0 $(4.43 \%)$ and $20: 0(0.58 \%)$ fatty acids. 


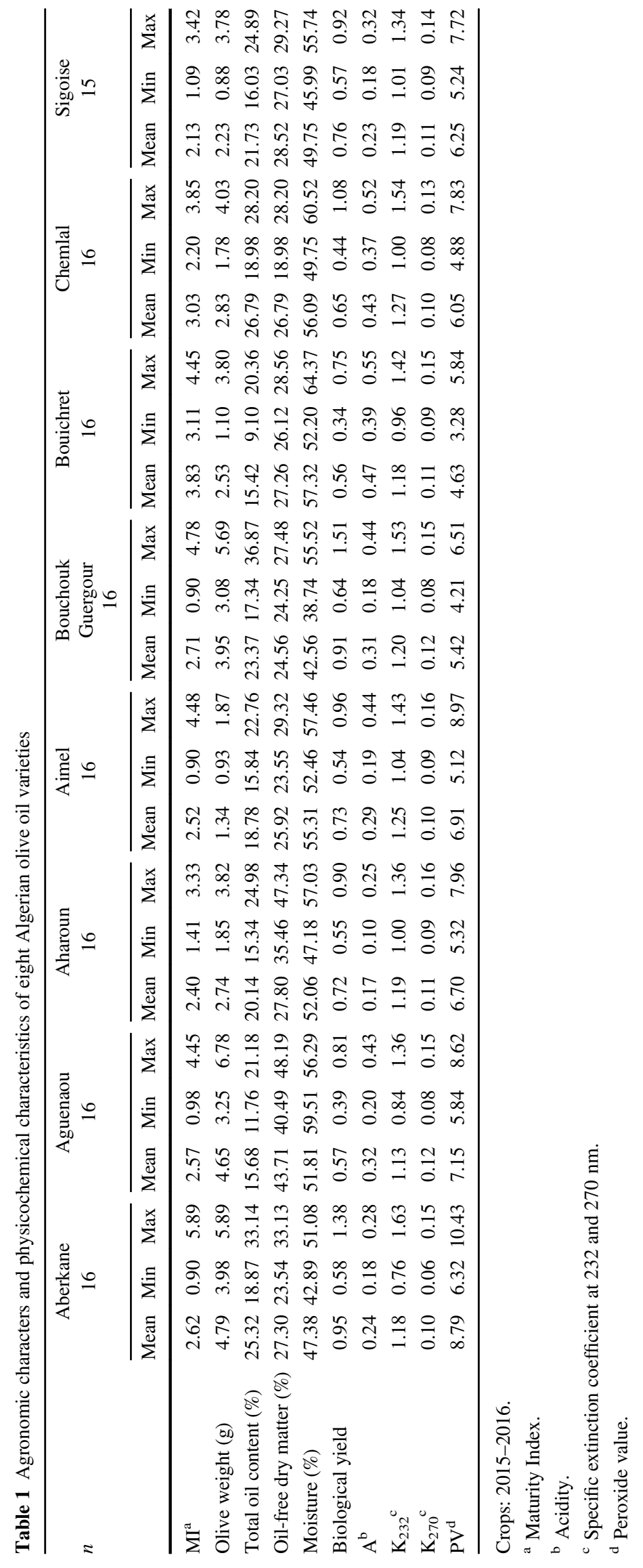




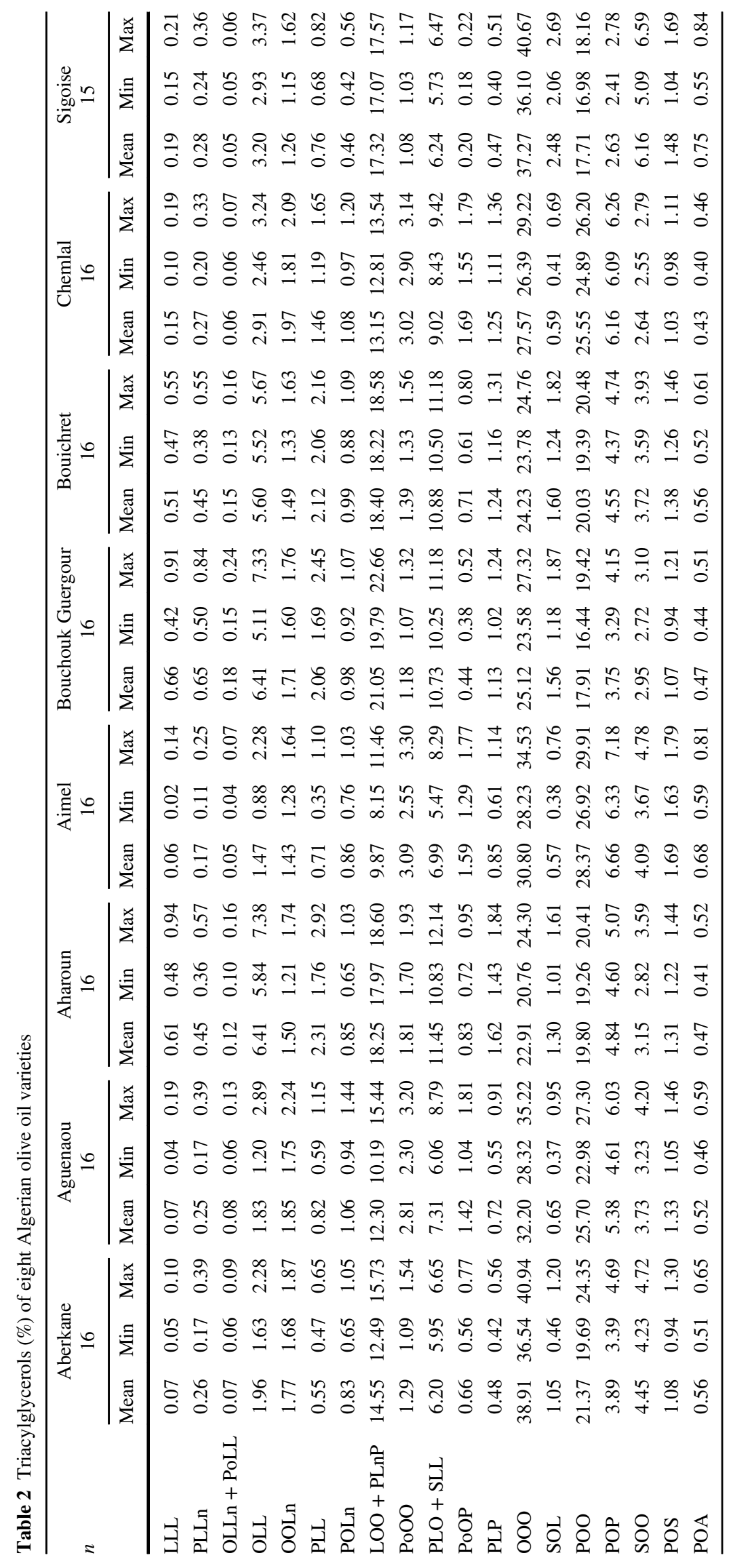




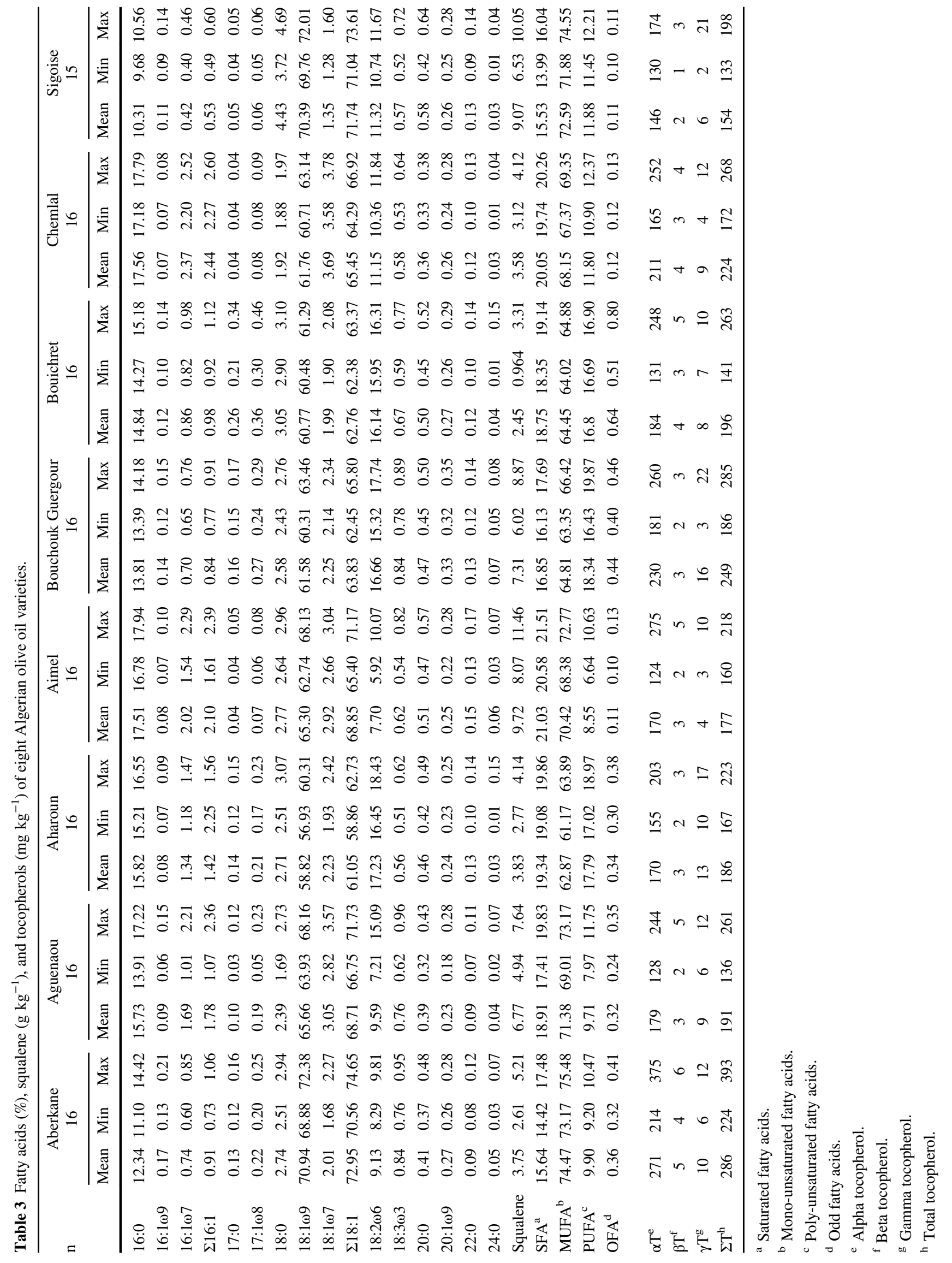


In literature, the few available data about Algerian VOO are not in sufficient detail regarding the individual quantification of the fatty acids. Thus, they do not allow comparisons with the results of this study.

\section{Influence of Ripening on TAG and Fatty Acid Compositions}

The most relevant variables affected by ripening are OOO,

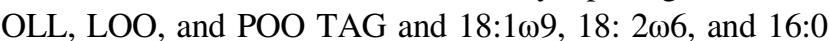
fatty acids. PLnP is co-eluted with LOO but its content is very low due to low content of Ln. A scatter plot of each TAG vs. its constitutive fatty acids according to MI of samples provides the direction of variable variation for each variety (Fig. 1). As expected, these variables are correlated. According to ripening (indicated by MI number on scatter plots), OOO increases for Aberkane, Bouichret, and Sigoise as 18:109 while both these variables decrease for Aguenaou, Aharoun, Aimel, Bouchouk Guergour, and Chemlal (Fig. 1 a). OLL and LOO remain almost constant for Bouichret and Sigoise and increase for the other varieties (Fig. 1 b-e). These variations result from the increase of 18:2 $\omega 6$ attenu-

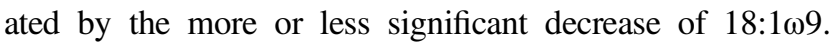
POO decreases for all varieties; this results from the decrease

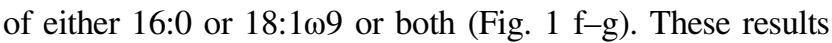
show that the variation of the TAG and fatty acid compositions according to ripening depends on the variety.

\section{Morphotypes}

It is difficult, from Tables 2 and 3, to assess to the similarities and differences between oil varieties. Therefore, TAG and fatty acid morphotypes (Fig. 2 and Fig. 3), that allow the visual establishment of characteristics for oil varieties (Pinatel et al., 2014) have been established for the eight Algerian varieties studied in this work. Aharoun, Bouchouk Guergour, and Bouichret show similar TAG morphotypes (Fig. 2) with high proportions of LLL, OLnL, PLnL, and LOL. On the other hand, Aguenaou and Aimel morphotypes show high values of POP, POO, and SOP. The three other cultivars show very different TAG morphotypes that allow easy characterization. Each cultivar shows typical fatty acid morphotypes (Fig. 3). For example, that of Bouchouk has a spreading shape, whereas that of Sigoise is very tight and very different from all the others. Thus, the use of fatty acid morphotypes is more relevant when one wants to carry out varietal traceability.

\section{Squalene Content}

Squalene $(2,6,10,15,19,23$-hexamethyl-2,6,10,14,18,22-tetracosahexaene), a triterpenoid hydrocarbon, is the main compound of the unsaponifiable matter of the VOO and represents over $90 \%$ of the hydrocarbon fraction. Squalene is a natural antioxidant that contributes to olive oil stability under light exposure (Boskou, Blekas, \& Tsimidou, 2006). As shown in Table 3, Aimel and Sigoise cultivars have the highest mean quantities of squalene $\left(9.72\right.$ and $9.07 \mathrm{~g} \mathrm{~kg}^{-1}$, respectively) while the lowest squalene contents are observed for Bouichret and Chemlal cultivars (2.45 and $3.58 \mathrm{~g} \mathrm{~kg}^{-1}$, respectively). These results cannot be confirmed by the literature because there was no other study on squalene content in Algerian olive oils. However, the values obtained are in the range of squalene contents described in olive oils, ie 0.2 to $12 \mathrm{~g} \mathrm{~kg}^{-1}$ (Boskou et al., 2006).

For all varieties studied, the trend lines of the squalene content in oils indicate a decrease depending on the ripening index; this agrees with results for 11 Italian varieties (De Leonardis, Maccioma, \& De Felice, 1998) and for two main Tunisian varieties (Chemlali and Chétoui) (Baccouri et al., 2008). However, the decrease of the squalene content as a function of MI is not similar for all varieties and it is lower for Aharoun and Bouichret than other varieties. Squalene is the biosynthetic precursor of the triterpenic pathway (triterpenic alcohols, methyl sterols, and sterols). The increase of phytosteroid content explains the decrease of squalene content with ripening (Sakouhi, Herchi, Sbei, Absalon, \& Boukhchina, 2011).

\section{Tocopherol Contents}

Tocopherols, only synthesized by photosynthetic organisms, are important compounds in VOO because they exert an antioxidant action (DellaPenna \& Pogson, 2006). Three tocopherol isomers were detected and quantified in the oil samples, $\alpha$-tocopherol, $\beta$-tocopherol, and $\gamma$-tocopherol; $\delta$-tocopherol was not detected in these oil samples. This result confirms the absence of $\delta$-tocopherol detectable indicated in a recent work of Tunisian VOO (Laroussi-Mezghani et al., 2016).

Table 3 presents the results for all samples from the eight cultivars. As expected, in all the analyzed samples, $\alpha$-tocopherol is the main isomer probably because it is the main final product of the biosynthetic pathway of tocopherols (DellaPenna \& Pogson, 2006). As was also observed by Beltrán et al. (2010) in VOO from around 30 olive cultivars grown in the World Olive Germplasm Bank of Córdoba, Spain, the variety seems to be a source of variability for the total tocopherols. For all studied varieties, the $\beta$-tocopherol content is always smaller than the $\gamma$-tocopherol content.

The highest average content of total tocopherols was observed in Aberkane (286 mg kg-1) followed by Bouchouk Guergour (249 $\mathrm{mg} \mathrm{kg}^{-1}$ ), and Chemlal oils (224 mg $\mathrm{kg}^{-1}$ ). Aguenaou, Aharoun, and Bouichret showed almost the same average content of total tocopherols (around $190 \mathrm{mg} \mathrm{kg}^{-1}$ ). The lowest total tocopherol contents were measured in Aimel and Sigoise (177 and $154 \mathrm{mg} \mathrm{kg}^{-1}$, respectively). However, the low antioxidant action induced 


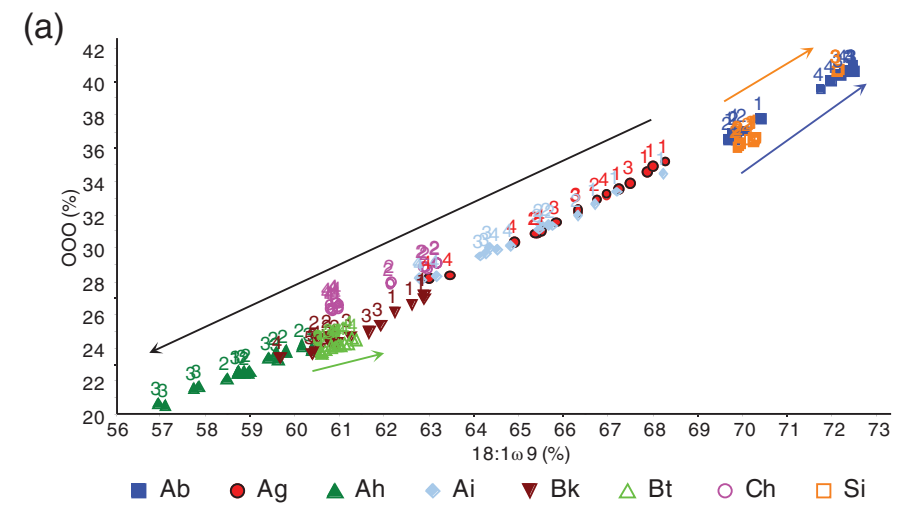

(b)

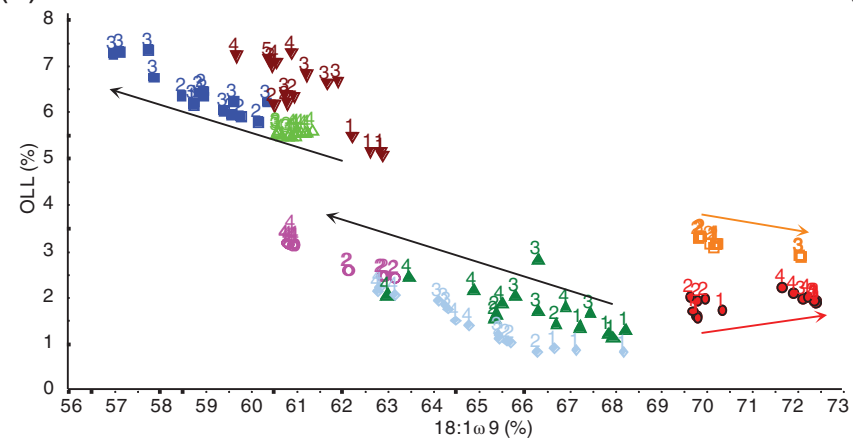

(c)

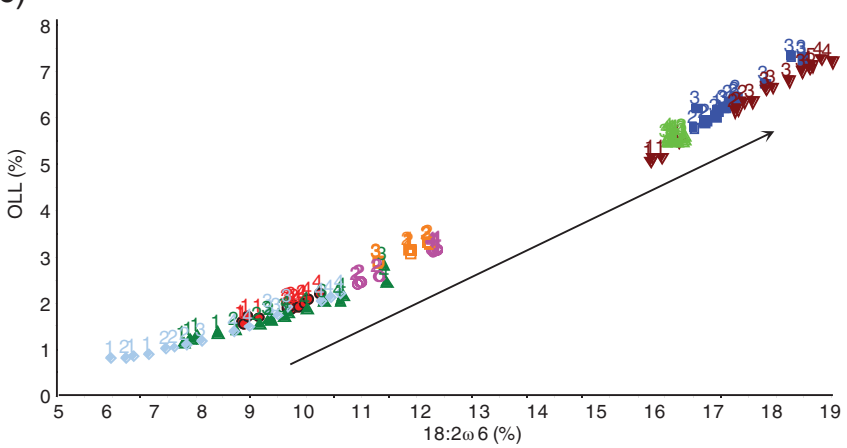

(d)

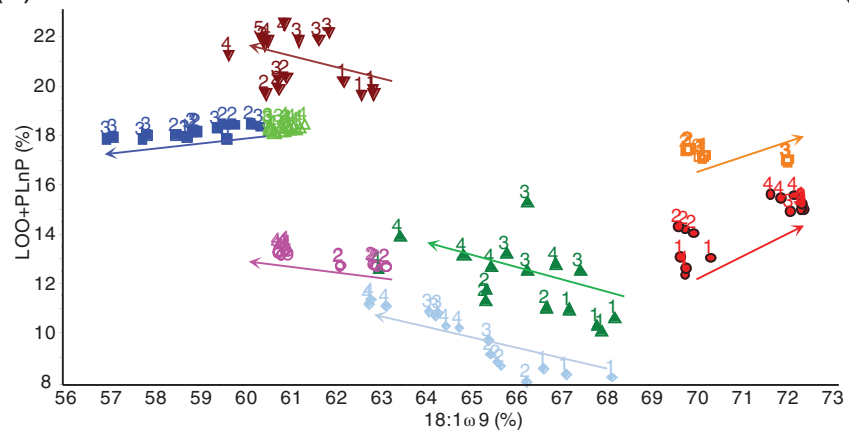

(f)

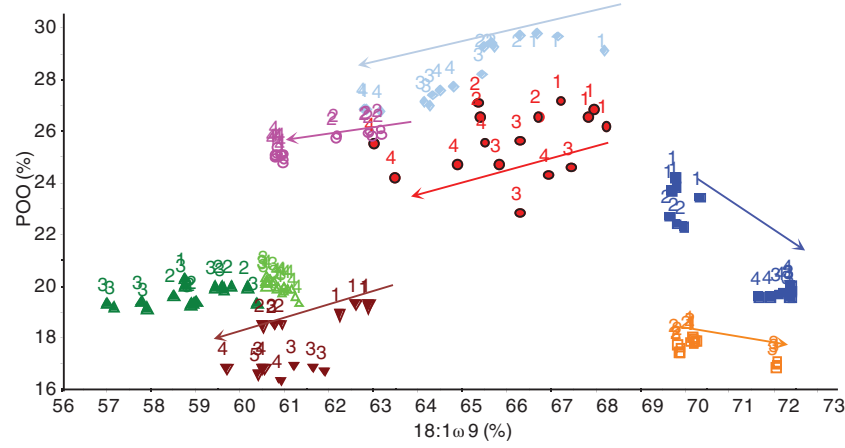

(e)

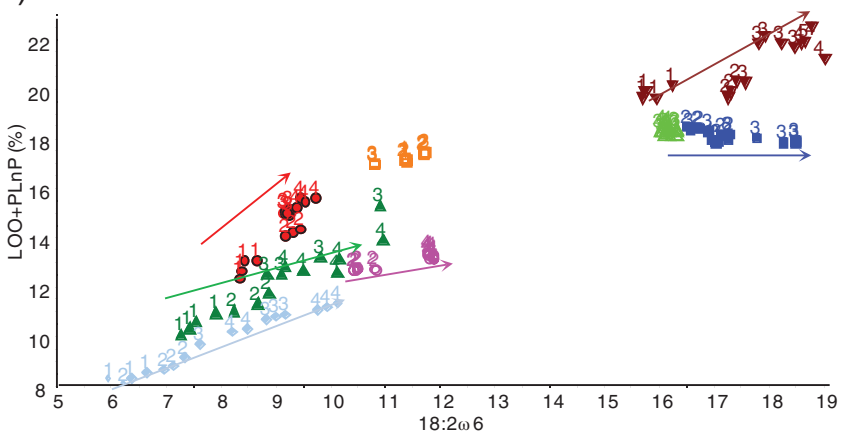

(g)

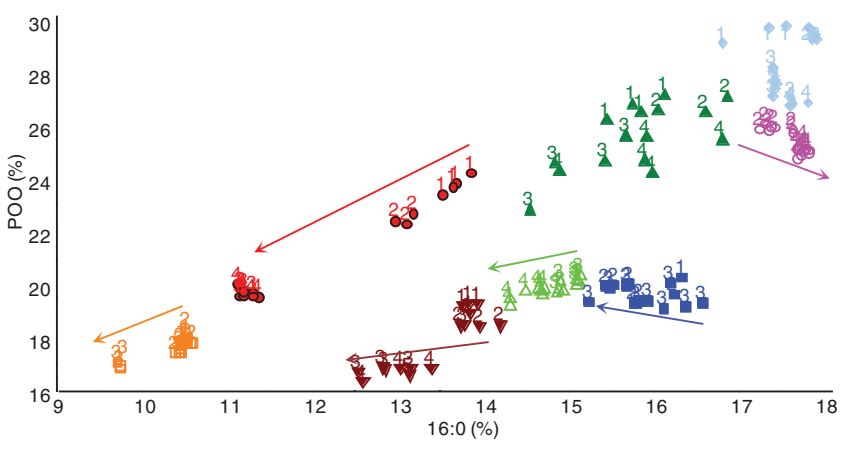

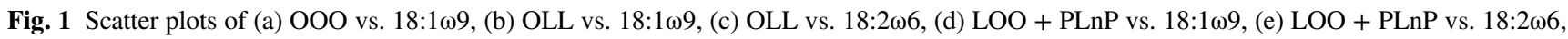
(f) $\mathrm{POO}$ vs. 18:1 $\omega$ and (g) POO vs. 16:0.Number on plots corresponds to maturity index (MI); Ab: Aberkane; Ag: Aguenaou; Ah: Aharoun; Ai: Aimel; Bk: Bouchouk Guergour; Bt: Bouichret; Ch: Chemlal; Si: Sigoise 


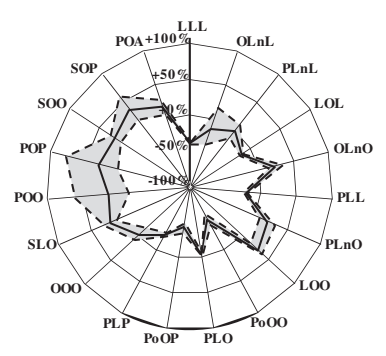

Aberken $\mathrm{n}=16$

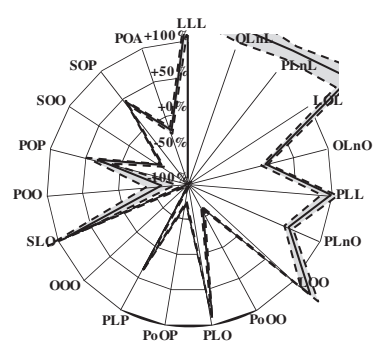

Bouchouk Guergour $\mathrm{n}=16$

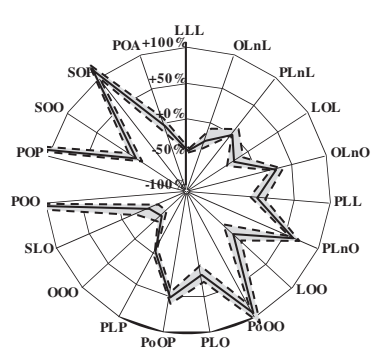

Aguenaou $\mathrm{n}=16$

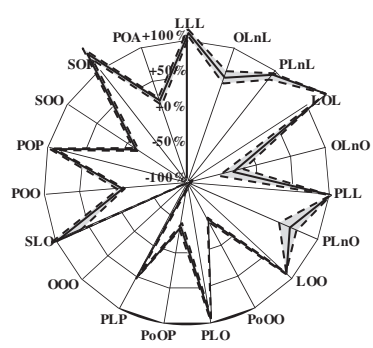

Bouichert $\mathrm{n}=16$

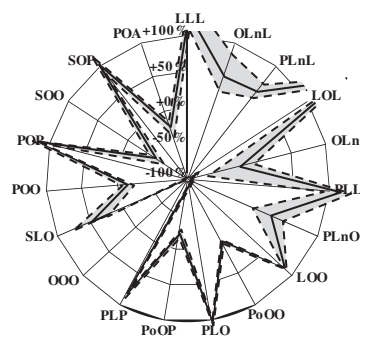

Aharoun $\mathrm{n}=16$

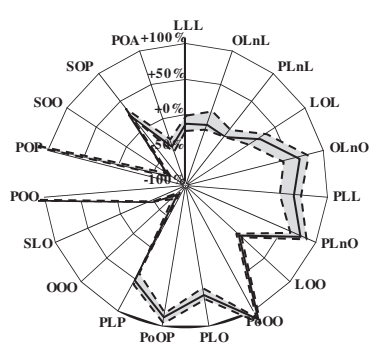

Chemlal $\mathrm{n}=16$

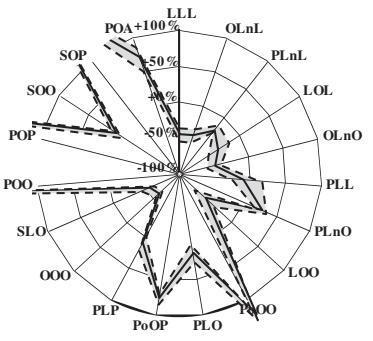

Aimel $\mathrm{n}=16$

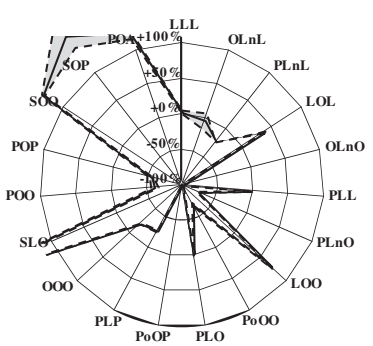

Sigoise $\mathrm{n}=15$

Fig. 2 "Morphotypes" from triacylglycerols of eight Algerian virgin olive oil varieties

should be offset by the squalene, which exhibits the highest levels for these two cultivars.

$\alpha$-Tocopherol mean levels varied from 146 (Sigoise) and $271 \mathrm{mg} \mathrm{kg}^{-1}$ (Aberkane). The $\beta$ - and $\gamma$-tocopherol mean ranges were between $2 \mathrm{mg} \mathrm{kg}^{-1}$ (Sigoise) and $5 \mathrm{mg} \mathrm{kg}^{-1}$ (Aberkane), and $4 \mathrm{mg} \mathrm{kg}^{-1}$ (Aimel) and $16 \mathrm{mg} \mathrm{kg}^{-1}$ (Bouchouk Guergour). These results are consistent with those found by Douzane et al. (2012) for the $\alpha$-tocopherol content of two Chemlal samples $\left(\approx 189.86\right.$ and $\left.180.02 \mathrm{mg} \mathrm{kg}^{-1}\right)$. Laincer et al. (2016) have determined the $\alpha$-tocopherol content of oils from 19 Algerian VOO varieties. Contents found for one sample from four varieties (Aberkane [220.2 mg $\mathrm{kg}^{-1}$ ], Aimel [252.2 $\mathrm{mg} \mathrm{kg}^{-1}$ ], Bouchouk Gergour [233.9 mg $\left.\mathrm{kg}^{-1}\right]$, and Bouichret $\left[207.5 \mathrm{mg} \mathrm{kg}^{-1}\right]$ ) are into the variation range of results reported in Table 3. On the other hand, the $\alpha$-tocopherol content of two of the three Chemlal samples (204.8, 263.9 and $317.4 \mathrm{mg} \mathrm{kg}^{-1}$ ) and the Sigoise sample $\left(384.9 \mathrm{mg} \mathrm{kg}^{-1}\right)$ is higher than the maximum found in this study.

The variation of total tocopherols is that of $\alpha$-tocopherol because it is the main isomer among the three tocopherols. Aberkane, Aguenaou, and Aimel show a decrease of the $\alpha$-tocopherol content according to MI. Chemlal has a very low decrease while Aharoun, Bouchouk Guergour, Bouichret, and Sigoise show a slight increase. Literature data show different behaviors depending on the varieties. $\alpha$-Tocopherol content of Cornicabra varied slightly during ripeness and a clear trend for this variety is not clear (Salvador, Aranda, \& Fregapane, 2001). $\alpha$-Tocopherol decreased with ripening for
Cobrançosa, Madural, and Verdeal Transmontana (Matos et al., 2007). $\alpha$-Tocopherol content in Chemlal remained practically constant until MI 3.5 and then decreased in the last stages. For Chetoui samples obtained in a rain-fed system, the levels of $\alpha$-tocopherol do not evidence a univocal trend during olive ripening (Baccouri et al., 2008). Therefore, there is no general trend that reflects the variation of the $\alpha$-tocopherol content according to ripening depending on the variety.

\section{Exploratory Data Analysis by PCA}

As a large quantity of variables has been obtained on each sample (percentages of 19 TAG and 14 fatty acids and concentrations of squalene and three tocopherols), it is not easy to obtain insights into how these measured variables result in some samples being similar, or how some samples differ from each other. Several PCA using TAG percentages and fatty acid percentages as variables, alone or associated together, with or without squalene concentration and/or tocopherol concentrations, have highlighted some sample groups. Figure 4 shows the results of PCA performed using the TAG, fatty acids and squalene together. This PCA provides the best distinction between the samples with respect to their varietal origin. It turns out that adding tocopherol variables does not improve the segregation of samples.

The score plot PC1/PC2 (Fig. 4 a) $(69 \%$ of the total variance of the original data set explained and, respectively, 12.58 and 10.88 as eigenvalues) shows three large groups of samples: Aharoun, Bouchouk Guergour, and Bouichret on 


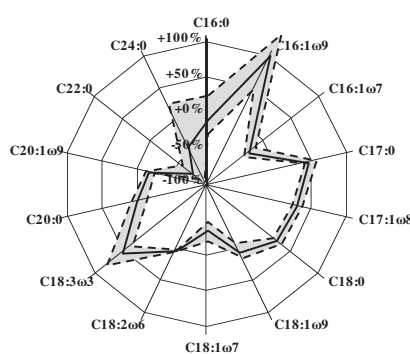

Aberken $\mathrm{n}=16$

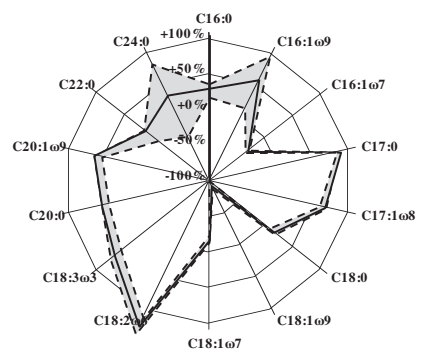

Bouchouk Guergour $\mathrm{n}=16$

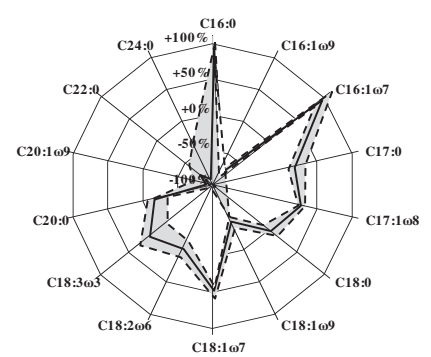

Aguenaou $\mathrm{n}=16$

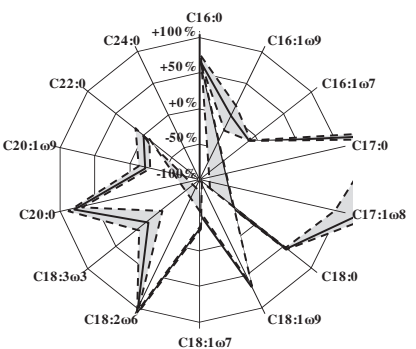

Bouichert $\mathrm{n}=16$

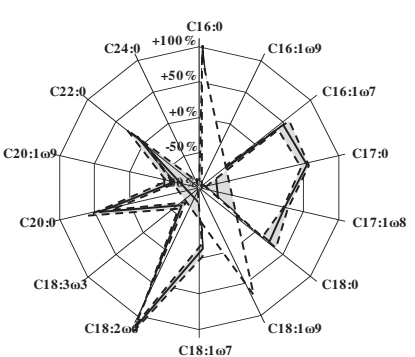

Aharoun $\mathrm{n}=16$

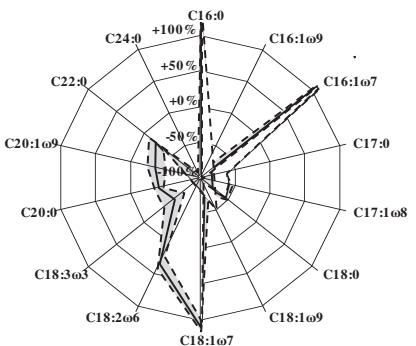

Chemlal $\mathrm{n}=16$

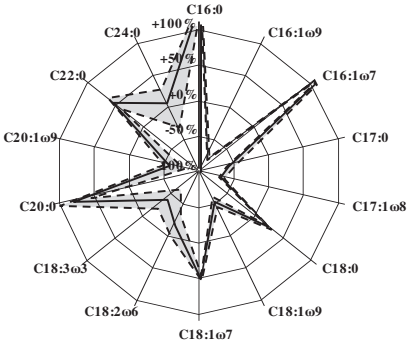

Aimel $\mathrm{n}=16$

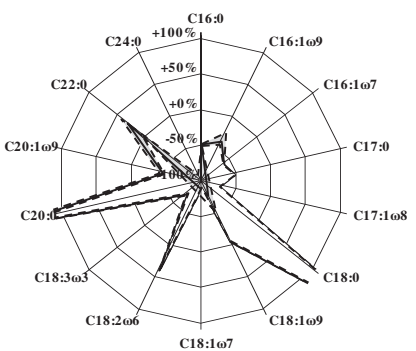

Sigoise $\mathrm{n}=15$

Fig. 3 "Morphotypes" from fatty acids of eight Algerian virgin olive oil varieties

the lower-right quadrant, Aguenaou, Aimel, and Chemlal on the lower-left part and Aberkane and Sigoise on the upper part. The first group is distinguishable by OLL, LLL, PLLn,
LOO, and 18:2 $\omega 6$ also projected on the lower-right quadrant of the loadings plot (Fig. 4 b). Aguenaou, Aimel, and Chem-

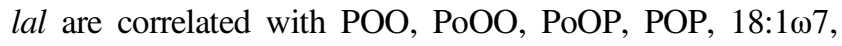

(a)

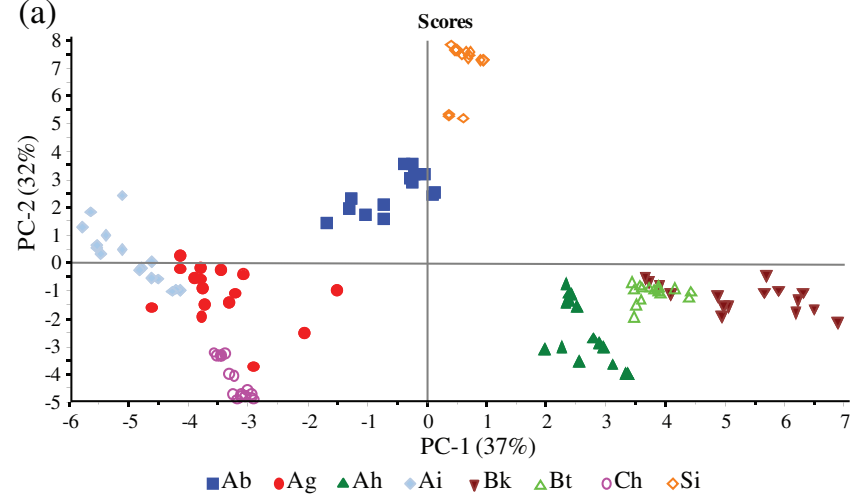

(c)

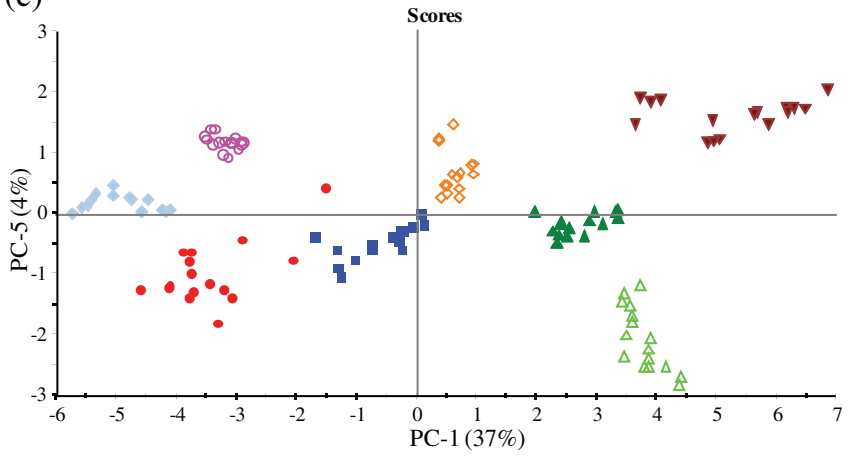

(b) Correlation Loadings $(\mathbf{X})$

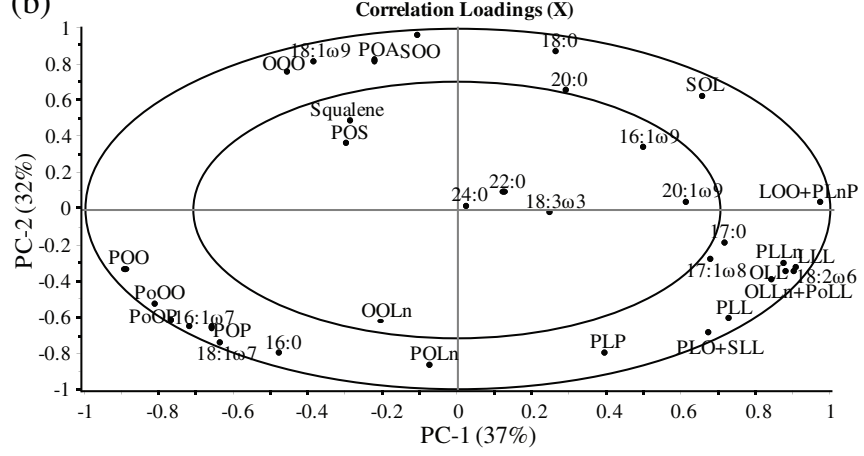

(d)

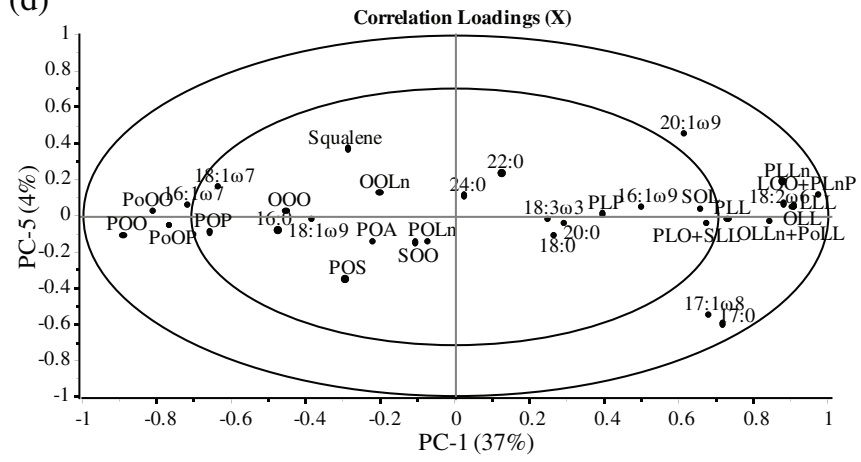

Fig. 4 Score plots $(a, c)$ and loading plots $(b, d)$ of principal component analysis performed on triacylglycerol and fatty acid percentages and squalene content. Ab: Aberkane; Ag: Aguenaou; Ah: Aharoun; Ai: Aimel; Bk: Bouchouk Guergour; Bt: Bouichret; Ch: Chemlal; Si: Sigoise 
Table 4 Percentages of correct classifications $(\% C C)$ of the eight varietal models for three SIMCA classifications with triacylglycerol and fatty acid percentages and squalene content

\begin{tabular}{lrrrrrrrrrrr}
\hline Models & \multicolumn{1}{c}{$\mathrm{Ab}$} & \multicolumn{1}{c}{$\mathrm{Ag}$} & \multicolumn{1}{c}{$\mathrm{Ah}$} & \multicolumn{1}{c}{$\mathrm{Ai}$} & \multicolumn{1}{c}{$\mathrm{Bk}$} & $\mathrm{Bt}$ & $\mathrm{Ch}$ & $\mathrm{Si}$ & $N_{\text {cal. set }}$ & $N_{\text {test set }}$ & $N_{c}$ \\
\hline$\# 1$ & 97.7 & 97.7 & 100.0 & 95.3 & 100.0 & 97.7 & 100.0 & 100.0 & 84 & 43 \\
$\# 2$ & 100.0 & 100.0 & 97.6 & 100.0 & 95.2 & 97.6 & 100.0 & 100.0 & 85 & 42 \\
$\# 3$ & 100.0 & 97.6 & 97.6 & 100.0 & 97.6 & 95.2 & 95.2 & 97.6 & 85 & 42 \\
Mean & 99.2 & 98.4 & 98.4 & 98.4 & 97.6 & 96.8 & 98.4 & 99.2 & & & \\
\hline
\end{tabular}

Ab: Aberkane; Ag: Aguenaou; Ah: Aharoun; Ai: Aimel; Bk: Bouchouk Guergour; Bt: Bouichret; Ch: Chemlal; Si: Sigoise; $N_{\text {cal. set }}$ number of samples in the calibration set; $N_{\text {test set }}$ : number of samples in the test set; $N_{c}$ : number of samples correctly assigned.

16:1 $\omega 7$, and 16:0 projected on the lower-left part of the loadings plot. Aberkane and Sigoise are distinct from the others on the basis of SOO, POA, OOO, 18:0, and 18:109.

PC3 and PC4 also have eigenvalues higher than 1 but as discrimination on this plot is not clear, it is not presented. However, PC3 distinguish the Aimel group from the others on the basis of their composition of POS. The score plot PC1/PC5 (Fig. 4 c) $(41 \%$ of the total variance explained and, respectively, 12.58 and 1.36 as eigenvalues) shows a complete segregation of all except three Aguenaou samples into eight groups with respect of their varietal origin. Bouichret group is differentiated from others with 17:0 and

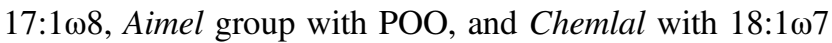
on loadings plot PC1/PC5 (Fig. 4 d).

\section{Varietal Origin Classification by SIMCA}

As the PCA with the complete data exhibits a tendency of the samples to cluster with respect to their varietal origin, it has been conceivable to constitute the individual PCA models based on the calibration sets for each variety, which then have formed the basis for the SIMCA classification.

As the number of samples was low, three SIMCA classifications were performed to obtain an idea of the change in the prediction when the composition of the calibration set and the test set is changed. For each SIMCA classification, a calibration set was formed with two-thirds of the samples from the eight varieties randomly selected for disjoint PCA. The associated test set was formed with samples not used in the calibration set. Mean centering was applied before modeling. The Fisher criterion value was set to 5\%. Table 4 gives the percentage of correct classification $(\% C C)$ of the three different test sets from three different calibration sets for the eight varieties. No sample was recognized as belonging to a variety that is not its own, but four to eight samples were not recognized by any of the eight varietal models (false negative). The best results were obtained with the second SIMCA classification, with 38 vs. 42 samples well predicted. The mean $\% C C$ varied from 96.8 to $99.2 \%$. These results are not unexpected: The models that lead to better prediction were those of the varieties that best distinguished using the PCA (Aberkane and
Sigoise), and the one that gave the worst predictions is that of the most difficult variety to differentiate (Bouichret).

\section{Conclusions}

The chemical compositions of TAG, fatty acids and squalene from eight Algerian varieties of olive oils aid in discriminating and enable varietal traceability of these oils. The composition of tocopherols is weakly discriminating. A visual representation of the TAG and fatty acid compositions (morphotypes) makes it possible to easily characterize the different varieties. A PCA, based on the compositions of TAGs, fatty acids, and squalene on several main components, distinguishes the groups in accordance with the varieties. The minor fatty acids and squalene that are rarely taken into account individually in published studies strongly participate in the differentiation of varieties. The classification by a supervised chemometric method (SIMCA) provides percentages of correct classification higher than $96 \%$ for all varieties. The approach carried out in this study can be used for the authentication of Algerian VOO.

\section{References}

Baccouri, O., Guerfel, M., Baccouri, B., Cerretani, L., Bendini, A., Lercker, G., ... Daoud Ben Miled, D. (2008) Chemical composition and oxidative stability of Tunisian monovarietal virgin olive oils with regard to fruit ripening. Food Chemistry, 109:743-754.

Bakhouche, A., Lozano-Sánchez, J., Bengana, M., FernándezGutiérrez, A., \& Segura-Carretero, A. (2015) Time course of Algerian Azeradj extra-virgin olive oil quality during olive ripening. European Journal of Lipid Science and Technology, 117:389-397.

Beltrán, G., Jiménez, A., del Rio, C., Sánchez, S., Martínez, L., Uceda, M., \& Aguilera, M. P. (2010) Variability of vitamin E in virgin olive oil by agronomical and genetic factors. Journal of Food Composition and Analysis, 23:633-639.

Boskou, D., Blekas, G., \& Tsimidou, M. (2006) In D. Boskou (Ed.), Olive oil chemistry and technology (2nd ed.). Champaigne, IL: AOCS Press.

Bouarroudj, K., Tamendjari, A., \& Larbat, R. (2016) Quality, composition and antioxidant activity of Algerian wild olive (Olea 
europaea L. subsp. Oleaster) oil. Industrial Crops and Products, 83:484-491.

De Leonardis, A., Maccioma, V., \& De Felice, M. (1998) Rapid determination of squalene in virgin olive oils using gas-liquid chromatography. Italian Journal of Food Science, 10:74-80.

DellaPenna, D., \& Pogson, B. J. (2006) Vitamin synthesis in plants: Tocopherols and carotenoids. Annual Review of Plant Biology, 57: 711-738.

Douzane, M., Nouani, A., Dako, E., \& Bellal, M. (2012) Influence of the variety, the crop year and the growing on the fatty acid and tocopherols composition of some Algerian virgin olive oils. African Journal of Agricultural Research, 7:4738-4750.

European Standard NF EN ISO 12966-2 (2011) Animal and vegetable fats and oils-gas chromatography of fatty acid methyl esters part 2: Preparation of methyl esters of fatty acids. La Plaine Saint Denis, France: AFNOR.

European standard NF EN ISO 9936 (2006) Animal and vegetable fats and oils-determination of tocopherol and tocotrienol contents by high-performance liquid chromatography. La Plaine Saint Denis, France: AFNOR.

Hadjou, L., Lamani, O., \& Cheriet, F. (2013) Labellisation des huiles d'olive algériennes : contrainte et opportunités du processus. New Medit, 2:35-46.

International Olive Council (2011) Guide for the determination of the characteristics of oil-olives COI/OH/doc. No. 1, November

International Olive Council (2015a). http://www.internationaloli veoil.org/

International Olive Council (2015b) Trade standard applying to olive oils and olive-pomace oils. /T.15/NC n ${ }^{\circ}$ 3/Rev. 10 (November).

International Union of Pure and Applied Chemistry (1987) Determination of triglycerides in liquid vegetable oils in terms of their equivalent carbon number by high performance liquid chromatography. Method $N^{\circ} 2324$. Standard methods of analyses of fats and derivatives. Oxford, England: Blackwell.

Jolliffe, I. T. (2002) Principal component analysis (2nd ed.). New York, NY: Springer.

Laincer, F., Iaccarino, N., Amato, J., Pagano, B., Pagano, A., Tenore, G., ... Randazzo, A. (2016) Characterisation of monovarietal extra virgin olive oils from the province of Béjaïa (Algeria). Food Research International, 89:1123-1133.

Laroussi-Mezghani, S., Le Dréau, Y., Molinet, J., Hammami, M., Grati-Kamoun, N., \& Artaud, J. (2016) Biodiversity of Tunisian virgin olive oils: Varietal origin classification according to their minor compounds. European Food Research and Technology, 242: 1087-1099.

Laroussi-Mezghani, S., Vanloot, P., Molinet, J., Dupuy, N., Hammami, M., Grati-Kamoun, N., \& Artaud, J. (2015) Authentication of Tunisian virgin olive oils by chemometric analysis of fatty acid compositions and NIR spectra. Comparison with Maghrebian and French virgin olive oils. Food Chemistry, 173:122-132.

Louadj, L., \& Giuffre, A. M. (2010) Analytical characteristics of olive oil produced with three different processes in Algeria. Rivista Italiana Sostanze Grasse, 87:186-195.
Matos, L. C., Cunha, S. C., Amaral, J. S., Pereira, J. A., Andrade, P. B., Seabra, R. M., \& Oliveira, B. P. P. (2007) Chemometric characterization of three varietal olive oils (Cvs. Cobrançosa, Madural and Verdeal Transmontana) extracted from olives with different maturation indices. Food Chemistry, 102:406-414.

Mezghache, M., Henchiri, C., Martine, L., Berdeaux, O., Aouf, N., \& Juaneda, P. (2010) Contribution à l'étude de la fraction insaponifiable de trois huiles d'olive issues des variétés Guasto, Rougette et Blanquette plantés dans l'est algérien. OCL, 17:337-344.

Moussaoui, R., Labbaci, W., Hemar, N., Youyou, A., \& Amir, Y. (2008) Physico-chemical characteristics of oils extracted from three compartments of the olive fruit (pulp, endocarp and seed) of variety Chemlal cultivated in Kabylia (Algeria). Journal of Food, Agriculture \& Environment, 6:52-55.

Moutier, N., Pinarel, C., Martre, A., Roger, J. P., Khadari, B., Burgevin, J. F., ... Artaud, J. (2004) Identification et caractérisation des variétés d'olivier cultivées en France. Turriers, France: Naturalia.

Ollivier, D., Artaud, J., Pinatel, C., Durbec, J. P., \& Guérère, M. (2003) Triacylglycerol and fatty acid compositions of French virgin olive oils. Characterization by chemometrics. Journal of Agricultural and Food Chemistry, 51:5723-5731.

Ollivier, D., Artaud, J., Pinatel, C., Durbec, J. P., \& Guérère, M. (2006) Differentiation of French virgin olive oil RDOs by sensory characteristics, fatty acid and triacylglycerol compositions and chemometrics. Food Chemistry, 97:382-393.

ONFAA Bilan de la campagne oléicole 2015/2016 (2016) Observatoire National des Filières Agricoles et Agroalimentaires. "Segment huile d'olive ». Alger, Algérie: Ministère de l'Agriculture, du Développement Rural et de la Pêche, 02, Rue des frères Ouadek Hacène Badi El Harrach.

Pinatel, C., Ollivier, D., Ollivier, V., \& Artaud, J. (2014) New approach to the determination of the origin of olive oils: Morphograms and morphotypes (part II). Olivae, 119:48-62.

Sakouhi, F., Herchi, W., Sbei, K., Absalon, C., \& Boukhchina, S. (2011) Characterisation and accumulation of squalene and n-alkanes in developing Tunisian Olea europaea L. fruits. International Journal of Food Science and Technology, 46:2281-2286.

Salvador, M. D., Aranda, F., \& Fregapane, G. (2001) Influence of fruit ripening on Cornicabra virgin olive oil quality. A study of four successive crop seasons. Food Chemistry, 73:45-53.

Wang, P., Sun, J., Zhang, T., \& Liu, W. (2016) Vibrational spectroscopic approaches for the quality evaluation and authentication of virgin olive oil. Applied Spectroscopy Reviews, 51:763-790.

Wold, S., \& Sjöström, M. (1977) Kowalski BR SIMCA: A method for analyzing chemical data in terms of similarity and analogy. Washington, DC: American Chemical Society.

World Catalogue of Olive Varieties (2000) International Olive Council. 154 Principe de Vergara 28002, Madrid, Spain

Zegane, O., Keciri, S., \& Louaileche, H. (2015) Physicochemical characteristics and pigment content of Algerian olive oils: Effect of olive cultivar and geographical origin. International Journal of Chemical Sciences, 1:153-157. 